\title{
Las relaciones Hispano-Británicas durante el reinado de Isabel II
}

\author{
Gemma Alonso TORRES
}

A lo largo de casi todo el siglo xIx, la política de España estuvo hipotecada en manos de los gobiernos francés y, preferentemente, inglés. Este hecho supuso una dependencia total de Paris y Londres.

Los acontecimientos políticos provocados por las guerras carlistas, la subida al trono de Isabel II y posterior reconocimiento de la reina, causaron un déficit en las arcas del Tesoro español, lo que motivó un endeudamiento continuo que se plasmó en la emisión de Deuda pública, adquirida por súbditos belgas, holandeses, franceses y principalmente ingleses.

A pesar de la insistencia, por parte británica, en que se amortizara la Deuda pública, y de las continuas reclamaciones de los Tenedores de bonos ingleses, ésto no tuvo lugar pues el Erario público español se encontraba en bancarrota.

La prensa británica, de gran influencia en Gran Bretaña, apoyó las reivindicaciones que estos británicos hicieron a través de sus políticos más representativos, como es el caso de su Ministro de Negocios Extranjeros, Palmerston, que aprovechaba todas las ocasiones que se le presentaban para exaltar el orgullo nacional inglés, llegando incluso a invocar una hipotética guerra entre Gran Bretaña y España, si no se consiguieran los fines buscados por la primera.

Después de muchas vicisitudes, los Tenedores únicamente consiguieron que, mediante el proyecto de Ley presentado por Bravo Murillo en el año 1851 , se redujera el capital efectivo rebajándolo del 4 y $5 \%$ al $3 \%$ anual.

La dilación en la amortización de la Deuda, influyó negativamente en las inversiones extranjeras, principalmente inglesas, en empresas industriales dedicadas al ferrocarril, de consecuencias nefastas para el despegue de la industria española durante el siglo xIX. 
Trasladando la importancia del pago de la deuda exterior española al terreno económico nacional, baste decir que el pago de los intereses de la Deuda pública y particular, motivó en el año 1883 una situación extrema que provocó la suspensión de la convertibilidad de los billetes en oro y se entró en una economía de tipo fiduciario que se extendió hasta finales del S. $X I X$.

\section{TENEDORES DE BONOS ESPAÑOLES}

Durante el reinado de Fernando VII, el 28 de octubre de 1828, se reconoció una Deuda con Gran Bretaña de 60 millones de reales en concepto de presos e indemnizaciones procedentes de la época de las guerras anteriores a esta fecha, siendo Ministro de Hacienda López Ballesteros.

La Comisión de Tenedores de Bonos Españoles (Spanish Bond Holders) ${ }^{1}$ se formó en el año 1844 y estaba compuesta por aquellos súbditos ingleses que en el año 1828 habian adquirido Deuda pública española, con el fin de, según sus propias palabras, "haber intentado coadyuvar al establecimiento de un gobierno constitucional en España» 2. Su finalidad era luchar por el cobro de esta Deuda. Así se manifestaron Thomas Cathbridge, Chard y Lthobes en la entrevista que mantuvieron con Istúriz ${ }^{3}$ en Londres, en la que le comunicaron su intención de hacer una transacción con el Gobierno español. A tal fin, habían nombrado como agente en la Corte a Henderson, que se pondría en contacto con el Secretario de Estado para tener una entrevista con Narváez y explicarle personalmente las reivindicaciones y solicitudes de los tenedores de bonos españoles.

A raíz de la formación de esta Comisión, se iniciaron los primeros contactos con el Gobierno español ${ }^{4}$, pero dado que en el año 1846, aún no

\footnotetext{
1 El tenedor de bonos es el que posee legítimamente una letra de cambio u otro valor endosable. Dentro de los tenedores podian distinguirse los «incautos" o pequeños inversores, en su mayoria extranjeros y los "expertos" o banqueros profesionales que invertían para obtener otras concesiones que les interesaban más. España no era un caso único, ya que estaba generalizado en la cuenca mediterránea y en la América latina.

2 IstúrIz, Ministro Plenipotenciario en Londres a Pacheco, Secretario de Estado. Londres 22 de abril de 1847. AMAE, MSs. 492, despacho $n^{\circ} 17$.

3 Francisco Javier de Isturiz y Montero, Ministro Plenipotenciario español en Londres.

4 Mon, Presidente Comisión tenedores Bonos a Narváez, Londres, 13 de noviembre de 1844 , AHN, legajo 5.602 .
} 
se había recibido contestación a estos primeros contactos, H. L. Bulwer, a la sazón Delegado de la Legación Británica en Madrid, se dirigió al Duque de Valencia recordándole que no se había tenido respuesta sobre el tema y solicitó la atención del Gobierno español sobre el problema suscitado por la negación del Gobierno español al pago de la Deuda inicial ${ }^{5}$.

Estos temas se trataban a nivel privado entre los dos Gobiernos, ya que el Gobierno inglés se sentía vivamente preocupado por el caso de los Tenedores de Bonos y además de sus reclamaciones, hacía hincapié en los efectos nefastos que podían generarse de no ser atendidas por el Gobierno español las reivindicaciones de los mismos ${ }^{6}$. En consecuencia, el Ministerio de Hacienda solicitó a los Presidentes de las Comisiones de Hacienda en París y Londres que remitieran a Madrid los cupones por conducto de la Embajada española en Francia y de la Legación en Londres ${ }^{7}$.

La preocupación del Gobierno inglés por el tema de los Tenedores de Bonos tuvo su culminación en el discurso que Palmerston pronunció en la Cámara de los Comunes el día 6 de julio de 1847, como contestación a la propuesta de George Bentwick ante la citada Cámara pidiendo al Gobierno Británico que adoptara medidas ante el Gobierno español para que se hiciera justicia a los acreedores ingleses del Estado ${ }^{8}$. La reclamación fue retirada pero se alcanzó el objetivo de la Comisión de Tenedores, ya que dio lugar a un destemplado discurso de Palmerston ante la Cámara, así como otro sobre el mismo tema de Brongham en la Cámara de los Lores.

Al dia siguiente de este discurso, el Presidente de la Comisión, D. Henning, solicitó a Istúriz una entrevista para que recibiera a una diputación con el fin de tratar las reclamaciones que no habían sido satisfechas por el Gobierno español ${ }^{9}$. Istúriz contestó a la citada solicitud que después del destemplado discurso de Palmerston en la Cámara de los Diputados, consideraba que este asunto sólo debería tratarse al más alto nivel, por lo que debería esperar órdenes del Gobierno español al respecto, antes de dar una contestación. En realidad, después de lo que había sucedido el día 6 de julio, Istúriz consideraba indecoroso recibir a esta Diputación ${ }^{10}$.

\footnotetext{
5 BULWER, Delegado Legación Británica en Madrid al Gobierno Español, Duque de Valencia, Londres, 25 de marzo de 1846, AHN, legajo 5.602.

6 Bulwer a PACHECo, Madrid 14 de abril de 1847, AHN, legajo 5.602.

7 Isturiz a PACheco, Londres 8 de junio de 1847, AMAE, Mss 492, despacho 48.

- Isturiz a PACheCo, Londres 8 de julio de 1847, AMAE Mss 492, despacho $n^{\circ} 80$

9 IStURIZ a PACHECO, Londres 7 de julio de 1847, AMAE, Mss. 492, despacho 82 y AHN, legajo 5.602 .

Istúaz a PACHECo, Londres 7 de julio de 1847, AHN legajo 5.602.
} 
Previamente a la solicitud por parte del Gobierno Español de un nuevo empréstito del Gobierno Británico, Salamanca intentó variar la opinión pública inglesa sobre el Gobierno Español. El 13 de julio de 1847, apareció en el periódico "Times» un artículo que decía: «Anuncio nuevo empréstito español de 100 millones de reales, sin producir ninguna alteración material en el valor de los fondos peninsulares, quedando estacionario durante el día» "1. También se mencionaba en el artículo que Salamanca ${ }^{12}$ había dirigido una carta a Henderson, Comisionado de la Asociación en Madrid, solicitándole «cualquier razonable proposición por parte de la Comisión".

En relación con esta última cuestión, Istúriz recibió una carta de Stokes, Secretario honorario de la Comisión de Tenedores de bonos, que según el - «Times»-, envió Salamanca a Henderson, en la que se proponía la entrega del $2 \%$ del interés y $12 \%$ del capital considerándolo como contribución a las exigencias del Estado pero no como amortización de la deuda, ya que el $12 \%$ no se cancelaría sino que circularía en la plaza. El proyecto tendría como finalidad defraudar a los acreedores por la suma del capital, poniendo a disposición del Gobierno fondos considerables ${ }^{13}$. En el periódico "Times" apareció un titular, dentro de "asuntos mercantiles", que decía: "Anuncio autorización empréstito español 100 millones de reales", lo que no produjo alteración en el valor de los fondos peninsulares ${ }^{14}$.

Henderson, ante la proposición' de Salamanca, envió a su hijo a Londres llevando en mano el mencionado escrito, deseando se consiguiera firmar un convenio que saldara la Deuda, pero en las condiciones siguientes: "Conversión total de la Deuda fondo $3 \%$, con la condición de que algunas ventas del Estado, así como el producto de aduanas y otros, se destinaran al pago del interés rebajado. Los tenedores deberian contribuir con una parte proporcional de sus bonos". Ponía como ejemplo: "Si se convirtieran 135 libras de bonos y cupones activos, los acreedores recibirían 120 libras y el Gobierno las 15 libras restantes. Para Henderson, la cesión del $2 \%$ de interés sobre la Deuda activa y la entrega del Gobierno de 8 millones de libras, era la obligación forzosa del Gobierno de dar bona fide del pago de intereses en el futuro. La Deuda pasiva de 1831 sería admitida a los precios convenidos previamente".

'IStúRIZ a PACHECO, Londres, 13 de julio de 1847, AHN, legajo 5.602.

12 Jose Salamanca, $M^{\circ}$ de Hacienda de 1842 a marzo de 1847 , fue comisionado por el Gobierno para la conversión de la Deuda exterior en Londres.

13 Istúriz a PACHECO, Londres, 13 de julio de 1847, AHN, legajo 5.062.

14 IstúRIz a PACHECO, Londres, 13 de julio de 1847, AMAE, Mss 492, despacho 87. 
La respuesta por parte de los tenedores no se hizo esperar. La Asociación de tenedores celebró una reunión o Junta pública en la “London Tavern» el día 15 de julio, Palmerston envió a una persona «inteligente" para que asistiera a la misma y así poder informar al Gobierno británico del asunto y de cómo se había desarrollado dicha sesión.

En el "Morning Post" apareció un artículo que decía: "Después de la conducta pérfida o el perjuicio repetido de las autoridades españolas, se desea que el público no tenga nada que hacer con este nuevo empréstito, siendo este asunto únicamente solucionable entre el poder ejecutivo de España y los contrayentes» ${ }^{15}$.

El Gobierno Británico, a través de Palmerston, apoyó las reivindicaciones de los tenedores e hizo frente a la actuación de Salamanca en relación con este asunto. Bentwick remitió a Istúriz un escrito en el que se hacía referencia al discurso pronunciado por Palmerston en la Cámara de los Comunes y alegaba en su favor que, como Ministro de Negocios Extranjeros, había actuado de manera similar respecto de Portugal, Nueva Granada y Venezuela y que únicamente necesitaba la ayuda de los Representantes del pais correspondiente para cobrar los intereses de las naciones que pudieran alegar pobreza, insolvencia e incapacidad bona fide para no cumplir con sus obligaciones ${ }^{16}$. Según Bentwick, los súbditos ingleses deberían pedir a sus Representantes que apoyaran a Palmerston en sus reclamaciones de 150 millones de libras, el total de la deuda de las naciones extranjeras al pueblo inglés. Al 3\% se convertiría en una Deuda total de 5 millones de libras, que aún no había sido pagada a los súbditos ingleses. Esta cantidad de 5 millones de libras era similar a la contribución sobre la propiedad y la renta (property \& income tax) y prácticamente igual al dinero pagado por Inglaterra en concepto de grano extranjero. Según Palmerston, si los deudores extranjeros hubieran pagado sus deudas, la cantidad de 6 millones de libras se habría reducido a un millón, recompensado el pago en metálico del interés sin el obstáculo de los descuentos del Banco y no habria provocado la miseria de los honrados comerciantes y fabricantes ingleses. Hacía mención al hecho de que España recibia como pago del azúcar manufacturado por manos esclavas, asi como por el café de Cuba y Puerto Rico, una cantidad mucho mayor que la que se debía a los súbditos ingleses, a costa de la honrada industria inglesa. Se hacia la siguiente pregunta: "Si las islas de Cuba y Puerto Rico producen

15 IstúRIz a PACHECO, Londres 13 de julio de 1847, AMAE, Mss 492, despacho 87.

16 BENTWICK a IstúrIZ, Londres, 13 de julio de 1847, AHN, legajo 5.602. 
más de 10 millones de libras, ¿cómo España no paga una deuda de 46 millones de libras a los súbditos ingleses?". Concluia Bentwick diciendo que «aunque Palmerston era su opositor político, merecía toda la confianza que los tenedores de bonos habian puesto en él, ya que no engañaría, traicionaría, ni retrocedería en sus actuaciones". También afirmaba Bentwick que "proseguiría con este asunto y que volvería a someter el tema de los tenedores de bonos ante la Cámara de los Comunes mientras tuviera aliento y no desfallecería en sus esfuerzos por problemática y difícil que se planteara la situación".

El Gobierno español no tardó en reaccionar al discurso de Palmerston. Pacheco hizo saber a Istúriz que el Gobierno español estaba adoptando resoluciones para mejorar la suerte de los tenedores de bonos, dejando traslucir que "quizás se hubiera tomado una resolución ahora, pero debido al discurso de Palmerston, se suspendian todas las gestiones y todo propósito al respecto». Asimismo, el Gobierno español autorizó a Istúriz que comunicara esta decisión a Palmerston e incluso, si éste lo solicitaba, entregarle una copia, con el fin de que lo pusiera en manos del Primer Ministro inglés, el liberal John Russell. También aprobaba el Gobierno español que no se recibiera por parte de Istúriz a la Comisión de la Asociación de Tenedores de bonos, ante la tensa situación suscitada por el discurso del día 6 pronunciado por Palmerston ${ }^{17}$.

El 15 de julio de 1847 tuvo lugar una reunión del Comité de la Asociación en la "London Tavern" en contestación a la oferta que les habia remitido Salamanca, a través de Henderson, Comisionado en Madrid de los Tenedores de Bonos, considerando que no estaban en situación de responder planteando ninguna proposición sobre el tema. Esta Comisión estaba formada por una Junta compuesta de 120 personas admitidas sin ninguna prueba o título de representación, por lo que presumiblemente entre ellos se encontrarían curiosos desocupados ${ }^{18}$.

La prensa británica, siempre de gran importancia en el panorama público y político de Inglaterra ${ }^{19}$, se hizo eco de los asuntos relativos a los tenedores de bonos; pero con ocasión de la reunión mantenida en la "London Tavern" no se tuvo conocimiento por la prensa del resultado de la misma. De todas formas se supo que el Presidente de la Junta había comentado el día de la reunión que "mientras España prosperaba, disminuian los

\footnotetext{
17 Pacheco a Istúriz, Madrid, 15 de jutio de 1847, AHN, legajo 5.602.

18 ISTÚaIz a PACHECo, Londres, 15 de julio de 1847, AHN, legajo 5.602, despacho 89.

19 Maurois, A., Historia de Inglaterra y de los ingleses, Barcelona, 1943, pág. 490.
} 
esfuerzos del antiguo Comité, siendo necesaria la formación de otro nuevo, teniendo como referencia las medidas que han sido tomadas por los tenedores de bonos belgas, holandeses, franceses e ingleses".

El Presidente del Comité remitió una carta a Istúriz, junto con el acta de la sesión pública de la Reunión celebrada en la "London Tavern», solicitándole que la hiciera llegar al Gobierno español. Por un lado, pedía que no se utilizara un lenguaje ofensivo contra "La Gran Nación Española», y por otro, amenazaba con acudir al Parlamento y al Gobierno británico con sus quejas a fin de obligar al Gobierno español al pago de las reclamaciones de los súbditos ingleses. Los periódicos ingleses se hicieron eco de la carta firmada por Henning, suavizando el escrito con la confianza plena de que España satisfaría su Deuda exterior. A pesar del gran período de tiempo transcurrido, tanto el Gobierno británico como el Parlamento y los tenedores de bonos creían que ya había llegado el momento de finalizar con los sufrimientos pasados durante este tiempo y no rechazaban que en caso de incumplimiento del pago, el Parlamento y el Gobierno pudieran intervenir en el asunto para conseguir la terminación del proceso, tal y como había propuesto Palmerston en su discurso del día 6 de julio ${ }^{20}$.

Durante todo el proceso de la amortización de la Deuda, la prensa británica siempre apoyó la causa de los tenedores. El día 23 de julio, apareció nuevamente un artículo en el periódico "The Times" ${ }^{21}$, en el que como eco de las reclamaciones de los Tenedores de Bonos se mencionaba «el grado de degradación que acompañaba hoy en día al nombre Españolm e incluso se hablaba de que el incumplimiento del pago por parte del Gobierno español, podría motivar una posible guerra entre ambos paises, aunque no existiera un apoyo manifiesto por parte de Inglaterra. Apuntaba como posible iniciación de la contienda Texas e iría extendiéndose hasta el Maine y gran parte de América del Sur. No obstante, el artículo del "Times" consideraba que esta posible guerra contra España, no sería justa, ya que el Gobierno español nunca habia negado durante todo este tiempo sus obligaciones, mientras que otros Estados Norteamericanos como Michigan, Mississipi, Indianas y otros, sí lo habian hecho. Aunque los deudores eran numerosos y el acreedor por contra sólo uno, no podria utilizarse el remedio más poderoso, ya que no sería el único, seria mucho más efectivo un repudio o expulsión por parte de la sociedad inglesa.

20 Henning, Presidente Comite Tenedores a Istúriz, Londres, 16 de julio de 1847, AHN, legajo 5.602 
"The Times» hacía hincapié en el hecho de que la soberana inglesa Victoria no había rehusado entrevistarse con los acreedores españoles y asimismo aconsejaba a las autoridades inglesas e incluso a la Monarquía, que únicamente se recibiera a los españoles para tratar asuntos políticos, pero que la Reina no los invitara ni los sentara a su propia mesa. Aconsejaba que se aplicara al Representante de unos tramposos la regla que se aplicaría al tramposo en particular, de este modo la Nación deshonrada no dudaría mucho tiempo en hacer un esfuerzo para purificar su maltrecha fama ${ }^{22}$.

Precisamente tuvo lugar en estas fechas el cierre del Parlamento Británico y como era de rigor, se invitó a las personalidades extranjeras acreditadas en la Corte de Londres, pero Istúriz en esta ocasión declinó la invitación. Las relaciones entre los dos Gobiernos, a raíz del discurso de Palmerston en la Cámara el dia 6 de julio —despreciativo para España y el Gobierno Español-, se habían convertido en unas relaciones difíciles y el Ministro Plenipotenciario español consideró como causas primordiales para su inasistencia que: $1^{\circ}$ ) Teniendo en cuenta que la representación española deberia situarse entre otros Representantes, Istúriz se encontraria en una situación embarazosa. $2^{\circ}$ ) Considerando que la asistencia por parte española no era imprescindible, podla dejarse abierto el camino para la actuación del Gobierno español. $3^{\circ}$ ) Istúriz prefería que se actuara, en consecuencia, pecando más por exceso que por falta de susceptibilidad ${ }^{23}$. Esta es la explicación que dio Istúriz para no entrevistarse con Palmerston, pues temía que dificultara las conversaciones que se estaban realizando entre los Gobiernos sobre un empréstito para el Banco de la Unión y el de San Fernando; también podían estropearse las gestiones del Comisionado sobre un contrato de azogues y la creación de 100 millones de billetes del Tesoro ${ }^{24}$.

Parece que los temores de Istúriz no se confirmaron, a tenor de la comunicación de Salamanca, ya que el éxito acompañó a las negociaciones para la obtención de un empréstito de 200 millones de reales para el Banco de San Fernando en Londres, que además contaba con todo el apoyo real ${ }^{25}$.

21 Este periódico fue creado en 1785 , convirtiéndose en uno de los tres principales periódicos ingleses junto con el "Morning Post", creado en 1772 y el "Daily News", fundado en 1846.

22 Istúlz a PACHECO, Londres, 23 de julio de 1847, AXN, legajo 5.602.

23 Istúriz a PACHEco, Londres, 23 de julio de 1847, AHN, legajo 5.602, despacho 100.

24 Istúniz a PaCheco, Londres, 20 de julio de 1847, AMAE, Mss 492, despacho 96.

25 Salamanca a Istúriz, Madrid, 28 de julio de 1847, PHN, legajos 8.528/29 
Como consecuencia de la publicación en los periódicos ingleses matinales de las sesiones de las Cámaras del día anterior, se planteó nuevamente el acierto de efectuar estas publicaciones, ya que el Conde Aberdeen, predecesor de Palmerston había comentado al Duque de Sotomayor, antecesor de Istúriz en la Legación española en Londres, la dificultad de llevar estos temas al terreno diplomático y que por tanto estas sesiones no deberían ser publicadas y dadas a conocer al gran público, aunque por lo general no tenía gran trascendencia - fuera del ámbito de las Cámaras-, entre los lectores ingleses ${ }^{26}$.

Siguiendo la táctica de los tenedores de bonos de publicar en la prensa diaria sus reclamaciones, Henderson, Presidente del Comité, lo hizo en la "Gaceta» del 22.VII.1847, rectificando las noticias publicadas por el Gobierno británico sobre el tema de los tenedores de bonos españoles. Casi todos los periódicos ingleses extractaron la noticia y muchos de ellos lo hicieron integramente ${ }^{27}$

El Gobierno Español efectuó las oportunas reclamaciones al Gobierno Británico por el discurso de Palmerston en la Cámara de los Comunes el día 6 de julio, ya que en este discurso no sólamente se había tratado el tema de los tenedores de bonos, sino que además se había aludido a la intervención española en Portugal en apoyo de la reina María Gloria, lo que habia producido un gran malestar y descontento en el Gobierno español.

Palmerston contestó a estas reclamaciones utilizando dos caminos diferentes; uno de ellos fue a través de Henry Lytton Bulwer, Legación Británica en España y el otro por medio de Istúriz. Palmerston explicó que fue "empujado" a su discurso, sin poder escoger ni el momento ni la oportunidad, ya que el conservador George Bentwick fue quien desde la oposición al Gobierno le habia obligado a hablar como contestación a su interpelación. Palmerston habia hecho gran hincapié en que las reclamaciones deberían trasladarse a los antiguos dirigentes del Gobierno español, pues los actuales únicamente llevaban en el cargo unos dos o tres meses ${ }^{28}$.

Según Palmerston, el único modo para finalizar el asunto sería que el Gobierno español actuara con justicia, comprendiendo que el actual Ministro llevaba pocos meses en el cargo, por lo que no era culpable de los actos de sus predecesores, aunque pensaba que podría ("make

26 Istúriz a PACHeCo, Londres, 17 de julio de 1847, AHN, legajo 5.602, despacho 103.

27 Istúriz a PACheCo, Londres, 3 de agosto de 1847, AMAE, Mss 492 despacho 104.

28 Joaguin Francisco Pacheco y GutiérRez Calderón detentó el Gobiemo desde el 28.111.47 hasta el $11.1 X .1847$. 
arrangements by which those omissions will be repaired") tomar medidas para que aquellas omisiones fueran reparadas ${ }^{29}$. Continuaba diciendo que lo más sensato sería que el Gobierno español tratara directamente con los acreedores, pero no fue óbice para hacer unas calificaciones injustas y despreciativas hacia el Gobierno español ${ }^{30}$.

Para Istúriz, las explicaciones de Palmerston se atrincheraban en el principio de los acreedores, primando sobre todo su satisfacción, al querer salvaguardar la responsabilidad del Ministerio actual, culpando a su predecesor, pues consideró estas explicaciones como una evasiva más que como una explicación ${ }^{31}$.

El Gobierno Británico actuaba de manera diferente según el ámbito donde se manifestara. Pacheco aprobó la actuación de Istúriz y las explicaciones de Palmerston sobre el tema del discurso del dia 6 de julio, aunque parece ser que el Gobierno británico, después que hubo manifestado privadamente al Gobierno español que no era una cuestión de Gobierno, había apelado a los sentimientos y buenos deseos del Gobierno español. A juicio de Pacheco, Palmerston habia demostrado no poseer un buen talante político, ya que habia querido presentar ante Istúriz el porvenir de España estrechamente vinculado a las consecuencias desastrosas de una guerra europea ${ }^{32}$.

A finales del mes de septiembre, el tema de los tenedores de bonos permanecía apoyado por la Cámara de los Comunes y por la prensa. Parece ser que el Gobierno británico no pensaba tratar este tema en el próximo viaje a Madrid de Browning, parlamentario británico ${ }^{33}$, aunque dado que el asunto se encontraba suspendido, según se había acordado el 15 de julio, sería conveniente no tratarlo por el momento.

A pesar de los momentos de tensión generados por el discurso de Palmerston, las relaciones diplomáticas no se rompieron; todo lo contrario, el Delegado de la Legación Británica en Madrid L. Bulwer recibió una condecoración de la Reina Isabel II como agradecimiento por el trabajo desempeñado ${ }^{34}$, aunque no cejaba en su empeño para que el Gobierno español atendiera las reclamaciones de los tenedores de bonos, pidiendo al Duque de Sotomayor que sometiera el asunto a las Cortes, reunidas en

33 ISTÜ

34 Madrid, 13 de septiembre de 1847, AMAE, Mss 492, despacho 136. 
noviembre para mantener el crédito de la Nación española y para devolver el dinero a quienes lo habian adelantado; se solicitó que el Gobierno español hiciera una proposición al respecto ${ }^{35}$.

El día 20 de noviembre de 1847 apareció en el "Morning Post» un artículo de 2 páginas bajo el título de "Meeting of Spanish Bond Holders", celebrado en la "London Tavern" del 19 de noviembre de 1847, presidido por Depster Henning, a la que asistieron entre otros Keyser, de Amsterdam, como diputado de los tenedores de bonos holandeses que se encontraban comprometidos en el mismo asunto ${ }^{36}$.

A pesar de la solicitud hecha por Bulwer al Duque de Sotomayor, el tema de los tenedores no se trató en las Cortes, aunque la explicación que dio el Duque al representante de la Legación inglesa en Madrid, fue que el Gobierno español deseaba satisfacer las justas reivindicaciones de los súbditos ingleses. En su opinión, también los súbditos españoles querian resolver el problema lo más pronto posible, debido a su gran cuantía, pese a que eran conscientes de la prioridad del arreglo de la Hacienda Española y preferian no hacer promesas prematuras. Para conseguirlo, en primer lugar, la Hacienda Española debería fortalecerse aún más, pero la última guerra civil había sido un gran obstáculo para ello ${ }^{37}$.

Estando el Duque de Valencia en el Gobierno, se pronunció a favor de solucionar definitivamente el desagradable asunto de la Deuda. El Duque de Valencia hizo unas declaraciones en favor de los tenedores de bonos: "el pais estaba cansado de buenas palabras y el Gobierno proponía llevar a las Cortes la cuestión de la Deuda extranjera". Estas palabras querían decir que los partidos políticos de España habian reconocido en los últimos 11 años la naturaleza sagrada de los créditos de los acredores extranjeros. Teniendo en cuenta que los ingresos del Erario habian aumentado notablemente, unido a la paz interior y exterior y contando con la mayoría de las Cortes, resultaba indudable que su ánimo era el de aliviar la situación de los acreedores ${ }^{38}$.

En el mes de marzo de 1848 se protestó una letra, con vencimiento el día 8, remesada para el pago del semestre. En virtud de la Deuda reconocida por el Tratado entre el Gobierno español y el Gobierno británico de 1828, se intentó cobrar por José Bermejo, Presidente de la Comisión de

\footnotetext{
35 BULWER al Duque de Sotomayor, Madrid, 8 de diciembre de 1847, AHN, legajo 5.602. Londres, 20 de noviembre de 1847, AHN, legajo 5.602.

Duque de Sotomayor a BULWER, Madrid, 8 de diciembre de 1847, AHN, legajo 5.602

HENNING al Duque de Valencia, Londres, 18 de diciembre de 1847, AHN, legajo 5.602
} 
Hacienda de España en Londres, pero todos sus esfuerzos fueron infructuosos, por lo cual quedó en suspenso el pago correspondiente hasta que no se recibieran fondos desde Madrid ${ }^{39}$.

Joaquín Scheidnagel, Presidente de la Comisión de Hacienda de España, sustituyó a Bermejo en su cargo, mantuvo una extensa correspondencia con Istúriz, en total casi 35 cartas y documentos desde el $1^{\circ}$ de enero al 28 de mayo de $1851^{40}$.

El último contacto que mantuvo la Comisión de Tenedores y el Gobierno español durante el año 1848, fue el envío de un memorial dirigido al Gobierno sobre las reclamaciones a su antecesor y al que se encontraba en funciones en el año $1848{ }^{41}$.

Como consecuencia de la ruptura de relaciones entre Gran Bretaña y España durante el mes de abril de 1848 hasta el año 1851, se suspendieron los contactos sobre el tema de los tenedores de bonos. A pesar de que no tuvieron lugar contactos a nivel de Legaciones, la Comisión de Tenedores continuó sus trabajos en favor de una resolución del problema. El nuevo Presidente Capel canalizó sus esfuerzos para lograr una nueva presentación de sus reclamaciones al Gobierno español ${ }^{42}$.

Pedro José Pidal, Ministro de Estado, remitió Orden a Istúriz aprobando la aceptación de una letra de 50.000 libras para el Presidente de la Comisión de Hacienda en Londres ${ }^{43}$.

En un "meeting" general de tenedores de bonos el 28 de octubre de 1850 , se adoptaron una serie de resoluciones para el pago de sus reclamaciones, redactado en grado de moderación, a pesar de que no se solicitaban grandes ventajas, pues querían comprometerse con la Nación española ${ }^{44}$

En el año 1851, se produjo un cambio en la actuación y forma de pensar del Gobierno Español sobre el tema de la Deuda extranjera. En el discurso de la Corona se hizo la solemne promesa de presentar a las Cortes con fecha 18 de junio, el proyecto de Ley para el arreglo de la deuda del

\footnotetext{
39 José Bermejo Presidente Comisión de Hacienda de España en Londres (posteriormente sustituido por Joaquin Scheidnagel el 11 de mayo) a ISTURIz, Londres, 6 de marzo de 1848, AHN, legajos 8.528/29 121.

Colección Istúriz-Baüer, Boletin de la Real Academia de la Historia, Madrid, 1919, pág.

41 Pidal, Ministro de Estado a Isturiz, Madrid, 21 de enero de 1848, AHN, legajo 5.602.

42 CAPEL, Presidente Comisión al Gobierno Español, Londres, febrero 1849, AHN, legajo 8.504 .

43 Colección Istúriz-Baüer, Ibidem, pag. 121.

44 Palmerston a Istúriz, Londres, 7 de noviembre de 1850, AHN, legajo 5.602.
} 
estado, en la que se encontraban los súbditos británicos, aunque el propio Gobierno reconocía que los recursos del país no le permitían cumplir completamente con los acuerdos adoptados con anterioridad, pero aceptaba que los tenedores de bonos habian hecho grandes sacrificios para permitir que España cumpliera con sus pagos ${ }^{45}$.

Este proyecto de Ley fue presentado por Bravo Murillo y constaba de 21 artículos. Su artículo $4^{\circ}$ se refería a los bonos de la ley del 16 de noviembre de 1834, que al no haberse presentado en los plazos fijados en la mencionada ley, se consideraban convertidos en $2 / 3$ del capital de la deuda consolidada del $5 \%$ y $1 / 3$ de la pasiva. En su artículo $8^{\circ}$ se reconocía que la nueva renta perpetua diferida del $3 \%$, empezaría a devengar intereses desde el $1^{\circ}$ de julio de 1851 , siempre que se presentaran antes del $1^{\circ}$ de octubre de 1851. La renta diferida devengaría un interés del $1 \%$ en los 4 primeros años, $1 / 4$ en los 2 años consecutivos y así a razón de $1 / 4$ cada 2 años hasta el decimonoveno en que se completaría el 3\%. En su artículo $13^{\circ}$, se consideraba que los extranjeros continuarian gozando de sus intereses aun en casos de guerra contra la Nación de cada uno de ellos ${ }^{46}$.

Por parte del Gobierno español se reconocía que era un gran sacrificio la reducción del capital efectivo, rebajándolo del $4 \%$ y $5 \%$ al $3 \%$ anual e incluso no podía aducirse como justificación la escasez del Tesoro español. Era incomprensible por parte española, considerar como hecho importante a favor de tomar estas medidas el que estos títulos hubieran pasado a manos de prestamistas y especuladores, dado que todavía existian grandes cantidades en manos de sus primitivos poseedores, que habian tenido que padecer que el papel original fuera anulado en 1823, reducido en 1834 y no se hubieran pagado sus intereses a causa de las desgracias públicas de la nación española.

Según la Junta que estudió el proyecto, después de diversas conversaciones con los representantes de los acreedores nacionales y extranjeros, se consideró este proyecto como el mejor arreglo, tanto para los interesados como para el posible porvenir de la Nación española.

La mencionada Junta resaltaba que Inglaterra, maestra en economía pública, nunca había hecho reducciones de crédito, respetando el valor nominal de los capitales y conciliando el derecho de los acreedores. La Junta reconocía que los acreedores sufririan un sacrificio de $2 / 5$ partes de su capital efectivo pero consideraba que otras Naciones en las

45 HowDEN al Marqués de Pidal, Londres, 27 de septiembre de 1850, AHN, legajo 5.602.
46 Diario de Sesiones de las Cortes, Apéndice $8^{\circ}$ al $n^{\circ} 13$, págs. 261/278. 
mismas circunstancias que España habian tomado las mismas resoluciones. Otro tema diferente lo constituian los cupones. El interés vencido constituía una obligación tan sagrada como el capital, debiendo efectuarse el reintegro en una época indefinida, mientras que el cupón imponía la obligación del pago en un plazo corto y a la vez determinado.

Dentro del proyecto, la Junta no consideraba fundada la capitalización al $3 \%$, apoyándose en el hecho de que los acreedores habian aceptado en 1841 , sin reclamación alguna, el decreto que satisfacía los intereses vencidos.

Según los estudios de la Junta, los dividendos supondrían para el Erario aproximadamente unos 160 millones de pesetas y convertirían los 6.000 millones de la deuda no consolidada en 780 millones al $3 \%$, gravando al Tesoro con 23 millones al año perpetuamente, que habria de ser añadida a la obligación de la deuda consolidada. La amortización de la deuda fue considerada por la Junta de estricta justicia, al urgir su pago mediante el capital obtenido por la venta de fincas y bienes que no fueran de utilidad para el Gobierno, ya que el Erario no podía consagrar dinero en metálico para su amortización y con el mínimo sacrificio, en un máximo de 20 años, se extinguiría una deuda embarazosa de 5.000 millones de reales. Según la noticia que apareció en el «Morning Post» y otros periódicos ingleses, el día 29 de agosto tuvo lugar una reunión entre Vonden, Daniel Weisveiller y Wertheim, Presidente del Comité de Amsterdam y co-delegado de los acreedores de Francia, Prusia y Bélgica, "opinaban que esta proposición debía ser aceptada por los tenedores de bonos".

Las desavenencias surgieron dentro del Congreso como consecuencia de la venta de los bienes para conseguir la amortización de la deuda, que debería hacerse forzosamente en papel, destinándose para ello valores propiedad del Estado. El dictamen de la Comisión sobre el proyecto de ley para el arreglo de la deuda pública, fijó en los presupuestos las cantidades anuales y progresivas que deberían destinarse al pago de intereses hasta 1870 inclusive, aplicándose los sobrantes, cada seis meses, a la amortización.

Los acreedores de la Deuda española, entre los que se encontraban súbditos ingleses, prusianos, de los Países Bajos y belgas intentaron, a través de sus respectivos Gobiemos, que intercedieran ante el Gobierno español para el arreglo definitivo de la deuda española como tenedores de sus bonos. El Gobierno español no consideraba apropiada la vía diplomática como cauce para esta reclamación ${ }^{47}$.

47 Escrito (minuta) desde Palacio a los Ministros de Negocios Extranjeros de Gran Bretaña, Prusia, Paises Bajos y Bélgica, Madrid, 14 de diciemhre de 1850, AHN, legajo 5.602. 
No obstante el largo período de tiempo transcurrido desde 1828 hasta el año 1851, exactamente 23 años, los acreedores ingleses no habían conseguido recuperar los 60 millones de Deuda, por lo que Howden volvió a reclamar al Gobierno español esta gran cantidad de Deuda, resaltando el gran lapso de tiempo transcurrido y el continuo incumplimiento de los acuerdos firmados por parte española; por contra, hizo hincapié en la gran moderación mostrada por los súbditos ingleses en sus continuas reclamaciones. Aunque la capitalización del 4 y $5 \%$, durante los 4 años siguientes, representaba una suma comparativamente pequeña para conseguir el pago total de 100.000 libras por año, considerando el lapso de tiempo transcurrido de 18 años, fue muy apreciada por parte inglesa. De cualquier manera los nuevos planes del Gobierno español contribuírían a mantener las buenas relaciones entre los dos países ${ }^{48}$.

La Secretaría de Estado del Gobierno español informó a los Gobiernos de Inglaterra y Holanda que se habia presentado un Proyecto de Ley en las Cortes para proceder al arreglo de la Deuda contraída por la Nación española, tanto dentro como fuera del Reino. El Gobierno español hizo hincapié en los esfuerzos que supondría este pago, ya que las condiciones económicas no eran todo lo buenas que se deseaban, debido principalmente a las guerras y disturbios anteriores a 1851 y pedía a los Gobiernos inglés y holandés que trataran el asunto con la inevitable reserva, dado que era un asunto privado entre el Gobierno español y sus acreedores ${ }^{49}$.

El Representante de la Legación Británica en España, Howden en nombre de su Gobierno, agradeció al Gobierno español sus buenas intenciones para el pronto pago de la Deuda, pese a reconocer que Ia situación económica era difícil, aunque lo achacaba al sistema vigente observado en España y no al país en sí. En forma un tanto adulatoria, deseaba toda la prosperidad posible a su «antigua, probada y digna aliada» ${ }^{50}$.

Durante el año 1852, parece que el asunto de los tenedores no tuvo ninguna variación, a excepción de un estudio realizado por Javier Istúriz sobre la documentación depositada en la Legación de España en Londres, en

48 Howden a Manuel Beltran de Lis, Primer Secretario de Estado, Madrid 5 de febrero de 1851, AHN, legajo 5.602.

49 Minuta de la Primera Secretaría de Estado firmado por Manuel Beltrán de Lis a los Ministros Plenipotenciarios de Inglaterra y Holanda, Madrid, 21 de febrero de 1851, AHN, legajo 5.602 .

50 Howden a Manuel Beltrán de Lis, Madrid, 24 de febrero de 1851, AHN, legajo 5.602. 
cuyo dossier aparecian reclamaciones defectuosas, otras copias originales y algunas reclamaciones desechadas. Según obraba en esta documentación, en el año 1836 se dieron instrucciones a Juan Antonio y Sages, Comisionado especial para verificar el cambio de documentos, así como para que «indagase extraoficialmente las cantidades satisfechas». Según Istúriz el Gobierno británico actuaría en reciprocidad exigiendo iguales demandas, por lo que creía conveniente que se actuara con urgencia ${ }^{51}$.

Las medidas tomadas por el Gobierno Español en 1851, trajeron como consecuencia la conversión de la Deuda diferida en cupones del $5 \%$ consolidado. El Comité inglés de Tenedores de bonos españoles en esta ocasión presidido por Daniel Weismeiller volvió a ponerse en contacto con las autoridades españolas y acordó en esta reunión recordar las reclamaciones ya expresadas en repetidas ocasiones al Gobierno recién formado, presidido por Roncali (conde de Alcoy) ${ }^{52}$. Se había admitido una conversión en Deuda diferida por la mitad de los cupones vencidos de los antiguos fondos del $5 \%$ consolidado, sin proveer la otra mitad. Los Comités de Londres, Amsterdam y Madrid, emitieron Certificaciones por esta última mitad. Así, aparece en Londres una Certificación por 3.529 .370 libras y en Amsterdam otra por 14.890.200 libras. De cualquier manera, en cuanto se propuso la reducción del valor de los cupones a la mitad de su valor, los acreedores, tanto nacionales como extranjeros, no cesaron en sus lógicas protestas. Cuando todo el mundo confiaba en la «honradez castellana" del Gobierno español, esta decisión provocó otro gran sacrificio para los tenedores de cupones, pues la intención del Gobierno español era anular la mitad de sus cupones. Weismiller pidió que se tomaran las medidas necesarias para reparar los daños cometidos, a fin de que la Nación española tuviera un mayor crédito en los mercados europeos. El Presidente solicitó que los Certificados que representaban la mitad de los cupones no admitidos en el último arreglo de la Deuda, fueran convertidos en Deuda del $3 \%$ diferido ${ }^{53}$.

El Gobierno español presidido por el Conde de Alcoy propuso, al final de su mandato, que se pagaran los cupones confiscados, lo que lógicamente produjo una gran satisfacción entre el Gobierno británico, los capitalistas, comerciantes y el público en general. El Presidente del Comité

Istúaiz a Secretaria de Estado, Londres, 22 de Mayo de 1852, AMAE, despacho 503.

52 FCo. Roncal, presidió el Gobierno de transición desde el 14.XII.1852 hasta 13.IV.1853, formado por militares.

53 Comité de Tenedores de Bonos Españoles a Gabriel de Aristizabal Reutt, Ministro de Hacienda, Londres 18 de diciembre de 1852, AHN, legajo 5.602. 
de bonos manifestó su satisfacción por la adopción de estas medidas, conocedor de que el Conde de Alcoy había tenido que enfrentarse, no sólo a la reputación de su país sino también a los futuros recursos necesarios para la Nación española, caso de no adoptar estas medidas ${ }^{54}$.

Gabriel de Aristizabal presentó un proyecto de ley durante el Gobierno presidido por el Conde de Alcoy, que sancionó el acto de reparación presentado a los Cuerpos Legisladores, lo que produjo que los Certificados del $50 \%$ suprimido de los cupones alcanzara en las Bolsas extranjeras un precio igual al tipo de transacción fijado en un 10,5\%. El Presidente del Comité inglés de Tenedores de Bonos españoles pidió al nuevo Gobierno presidido por Lerrundi ${ }^{55}$ que se agilizara la solución de la cuestión, no sólo por la liquidación definitiva de intereses legítimos, sino por considerarla como una "cuestión de honor para el Gobierno español»" ${ }^{56}$.

Durante el Gobierno de Sartorious ${ }^{57}$. Ignace Bauer, Presidente del Comité, llamó la atención de las autoridades españolas y apeló al sentimiento de justicia del Gobierno español. Argumentó que era de notoriedad universal el que los Tenedores de Bonos de los cupones de la antigua Deuda española del $4 \%$ y $5 \%$ habían hecho las oportunas reclamaciones en favor de sus intereses, ya que la ley de conversión no contemplaba más que la mitad del valor de los cupones, sin adoptar disposición alguna sobre la otra mitad. El 29 de marzo de 1853, se presentó a las Cortes un proyecto de ley por el que debía amortizarse esta Deuda, quedando los acreedores del Tesoro español satisfechos.

Como consecuencia de los acontecimientos políticos posteriores ${ }^{58}$ fue retrasada la liquidación de la Deuda hasta la reapertura de las Cámaras. Las medidas económicas a tomar, se explicaron en las Cámaras el 29 de septiembre, con la presentación de un nuevo proyecto de ley, pero sin contemplarse las disposiciones relativas a los cupones consignados. Esta omisión fue considerada contraria a los sentimientos de justicia y reparación de los tenedores ingleses. Se hizo hincapié en el hecho de que,

\footnotetext{
54 El Conde de Alcoy dimitó por la oposición militar.

55 Teniente General Francisco de Lerrundi, gobernó del 14 de abril de 1853 al 18 de noviembre de 1853.

56 Daniel Weismeiller, Presidente Comité Tenedores a Manuel Bermúdez de Castro, Ministro de Hacienda, enviado a través de la Legación Británica en España, Londres, 16 de abril de 1853 , AHN, legajo 5.602.

57 LuIS SARTORIOUS, conde de San Luis, gobernó desde el 18 de septiembre de 1853 al 8 de julio de 1854 .

58 El 10 de abril de 1853 se disolvieron las Cortes por el Conde de San Luis, ante la votación adversa y la discusión en el Senado por el escándalo de los ferrocarriles.
} 
España se encontraría con graves problemas para obtener recursos en el extranjero con los que poder acometer empresas colosales si no se ampliaban los compromisos adquiridos anteriormente. Por ello, se pidió nuevamente al Gobierno español que sometiera el proyecto de Ley a las Cortes ${ }^{59}$.

Teniendo en cuenta el cariz que iba tomando el tema del pago de la Deuda y de los cupones, el Comité de Tenedores acometió nuevamente su lucha pacifica para conseguir su total amortización, utilizando como en ocasiones anteriores a la prensa inglesa. En este caso fue el «Daily News» que publicó un artículo bajo el título de "SPANISH BONDHOLDERS". En este artículo se transcribía un artículo firmado por Howden, embajador británico en Madrid, dirigida al Presidente del Comité de Tenedores de bonos, en la que se aconsejaba enviar a un comisionado especial a Madrid para cooperar en la resolución definitiva y con éxito del asunto. Se pedía aunar esfuerzos en favor de las reclamaciones de los Tenedores, apoyándose en la declaración de moralidad del Gobierno español que estaba seguro no permitiría un error tan escandaloso como la confiscación de los cupones. Aunque la moda de todos los ministros españoles era protestar contra la interferencia diplómatica en este asunto, se decía, "Confío que la iniciativa partirá enseguida del Gabinete del Duque de la Victoria». A continuación el Comité pasaba a la intimidación, intentando presionar a la opinión pública española y al Gobierno español pues aseguraba que el público inglés tenía en sus manos prácticamente el remedio del problema, ya que no dudaría en recomendar a los capitalistas ingleses, grandes y pequeños, que no tuvieran nunca tratos económicos con España en ningún asunto, hasta que la cuestión de los cupones se arreglara satisfactoriamente, como garantía de cualquier pago subsiguiente en el futuro ${ }^{60}$.

Bauer, agente de los tenedores de bonos ingleses, se puso en contacto con el Ministro de Hacienda, achacando una conducta escandalosa al Ministro Bravo Murillo, de la se hizo eco toda la prensa europea. Insistía en la reiteración por parte del pueblo inglés de las reclamaciones para el pago de los "cupones confiscados". Reiteraba la insistencia de los súbditos británicos en que se corrigiera la mala fe y los pasados agravios provocados por un Gobierno que había enarbolado la bandera de la moralidad pública y privada ${ }^{61}$.

59 Ignace Bauer Presidente Comité Tenedores a J.F. Domenech, Ministro de Finanzas. Londres, 2 de diciembre de 1853, AHN, legajo 5.602.

6o Articulo del períodico "Daily News", Londres, 12 de agosto de 1854, AHN, legajo 5.602.

61 Howden a PACheco, Ministro de Finanzas español, Madrid, 21 de agosto de 1854, AHN, legajo 5.602 . 
Con la llegada al Gobierno como Presidente, por segunda vez, del General Espartero, Duque de la Victoria, los Tenedores de bonos ingleses recuperaron en parte sus perdidas esperanzas de obtener el $50 \%$ de los cupones atrasados. Para la opinión pública británica, el hecho de que se escogiera al conde de Luchana, para regir los destinos de España, constituía una garantía de reparación de la injusticia sufrida ${ }^{62}$. Se instó al Gobierno para que obtuviera de las Cortes Constituyentes los recursos necesarios para reparar esta injusticia en beneficio del crédito de España ${ }^{63}$.

A pesar de la confianza depositada en el Duque de la Victoria, los «desgraciados acreedores de la Nación española" se quejaban de que, independientemente de cual fuera el Gobierno español y de sus opiniones públicas y políticas, siempre recaía la injusticia sobre el extranjero, rechazando la Deuda justa. El Gobierno siempre contestaba al Comité -Organo de los agraviados-, de una manera estereotipada, aunque aquello menoscababa la honra nacional de España, en detrimento del pueblo inglés ${ }^{64}$. El Gobierno español siempre que recibía reclamaciones por parte de los súbditos ingleses o de su Gobierno, contestaba que no podia considerar aceptable la vía diplomática para dirimir el contencioso con los Tenedores, desviando las reclamaciones al Ministerio de Hacienda como único órgano apropiado para su resolución ${ }^{65}$.

En el año 1855, se dio al traste con las buenas expectativas despertadas por el Duque de la Victoria para la pronta y feliz resolución del tema de la Deuda. A través de Weismeiler y Bauer, agentes acreedores de los Tenedores de bonos, se comunicó al Gobierno español la enérgica protesta de los mismos por su supuesto consentimiento al arreglo del asunto de los cupones y a la aceptación de lo establecido. Por consejo de Howden, se depositó una copia de esta protesta escrita en manos de un escribano público ${ }^{66}$. Además, el apoyo dado unánimemente por los Ministros del Gobierno español a la decisión de las Cortes de no tomar en consideración la solicitud de los Tenedores de Bonos españoles, produjo sorpresa y tristeza en el Gobierno británico ${ }^{67}$ que pidió explicaciones al

62 El Conde de Luchana o Duque de la Victoria, después de la insurrección de 1843, acaudillada por Narváez, partió de España en el crucero británico Meteor, permaneciendo hasta 1854 desterrado en Londres.

63 Ignace Bauer a Pascual Madoz, Ministro de Hacienda, Londres, 7 de febrero de 1855 , AHN, legajo 5.602 .

64 Howden a Claudio anton luzuriaga, Primer Secretario de Estado, Madrid, 14 de febrero de 1855, AHN, legajo 5.602.

65 Primera Secretaría de Estado a Howden, Madrid, 21 de febero de 1855, AHN, legajo 5.602.

66 Howden a Claudio anton de Luzuriaga, Madrid, 1 de abril de 1855, AHN, legajo 5.602.

67 Howden a Claudio A. de L.uzuriaga, Madrid, 18 de mayo de 1855, legajo 5.602. 
Gobierno español sobre las razones que habian motivado el que se hubiera tomado esta decisión.

Para tratar el tema de la parte de la Deuda impagada por el Gobierno español, se mantuvo una reunión en Londres del Comité formado por las partes interesadas para tratar este tema con el Gobierno español, presidido por J. D. Powles. Después de la reunión se redactó un Memorial con 4 apartados: $1^{\circ}$ ) En el «meeting" se aprobaba completamente la representación enviada el 16 de abril por el Comité de Tenedores de Bonos españoles al Marqués de Miraflores, Presidente del Consejo de Ministros del Gobierno español, en la que se le rogaba recomendara al Gobierno importantes contenidos de la misma. $2^{\circ}$ ) Se quería advertir al Gobierno español que se conocía el incremento de recursos del país en los últimos años, que era incluso superior a todos los demás países europeos. $3^{\circ}$ ) Según prestigiosos juristas españoles, las reclamaciones de los Certificados tenian el respaldo de la justicia y la moralidad en sus lógicas ansias por conseguir un acuerdo. $4^{\circ}$ ) El Comité pidió que se hicieran llegar estas resoluciones al Gobierno español y se llegara a un final satisfactorio ${ }^{68}$.

El Gobierno británico siempre consideró, como suyo propio, el problema de los tenedores de bonos y por ello hizo un gran hincapié en resaltar y aumentar la posición que ocupaba España en aquella época (1855) entre los demás países europeos. Su finalidad era obligar a las autoridades españolas a zanjar el tema de los Tenedores de Certificados que se suscitó en 1851 , al convertir la mitad de la Deuda original firmada en $1828^{69}$.

Para tratar directamente este tema con las Autoridades españolas, Powles, Presidente del Comité de Certificados, llegó a Madrid desde Londres en octubre de 1858 aprovechando las amistosas relaciones entre España y Gran Bretaña -afianzadas por la corriente de vientos de paz que soplaba en Europa-. Estas relaciones habian producido un intercambio de invididuos, tanto a nivel de tratos comerciales como personales. Powles recordaba que, en tiempos pasados desdichados, el pueblo inglés prestó dinero a la Nación española y lo lícito sería que se devolviera el capital prestado por los súbditos ingleses. Durante cierto tiempo, se pagaron puntualmente los dividendos de sus préstamos y el crédito público de España tuvo un lugar destacado entre los poderes dirigentes de Europa.

\footnotetext{
68 "Resoluciones del Meeting entre el marqués de Miraflores y Powles. Presidente Comité de Tenedores de Certificados españoles". Londres, AHN, legajo 5.602.

69 Andrea Anchande a Saturnino Calderón Collante, Londres, 11 de octubre de 1858, AHN, legajo 5.602 .
} 
Pero posteriormente, con el cambio de la situación, se produjo una severa presión en las finanzas españolas, de hecho no se pagaron dividendos, llegando a alcanzar una cifra superior a 16 millones de libras. El 1 de agosto de 1851, se decretó el pago de la mitad con un interés anual del $1 \%$, sin previsión para el resto. Ante esta disposición, los Tenedores de Bonos formaron un Comité entre ellos mismos y bajo su autoridad se extendieron Certificados para cada tenedor por la cantidad de cupones impagados, a fin de que si se efectuaba una liquidación, se pagaria a cada tenedor la cantidad debida. No hay que olvidar, que estos Certificados no constituian ni título ni obligación.

El Gobierno español aún debía la mitad del importe total de la deuda y los Certificados representaban las partes tituladas de la otra parte. Para el pueblo inglés era el momento más propicio para efectuar el pago, ya que el panorama político era muy halagüeño gracias a la industria del pueblo español. Hay que tener en cuenta que esta mitad representaba la quinta parte del precio al que fueron comprados considerando que habian transcurrido siete años desde 1851. Se quejaba Powles del tiempo transcurrido, aunque por otra parte se alegraba de la buena situación del pueblo español. Al pueblo inglés le extrañaba como, habiéndose emitido bonos por la cantidad total de los atrasos con un interés anual del $3 \%$, podia haberse firmado el Decreto de 1851.

Además, estas medidas repercutieron negativamente en las transacciones, tanto en obligaciones nacionales como en participaciones en compañías públicas formadas para el transporte por ferrocarril y empresas industriales. Según los Estatutos del Stock Exchange de Londres, se prohibían todas estas transacciones. No podía olvidarse que, en esta época, la mayoría de las naciones europeas estaban extendiendo continuamente su red de ferrocarriles, por lo que pedian la cooperación a otros capitalistas europeos. Esto sucedía en Francia, Rusia, Austria, Prusia, Holanda, Bélgica, Italia, Cerdeña, Dinamarca y Suecia. Como estas Compañías cotizaban en Bolsa, España sería excluída consecuentemente de las de Inglaterra y Holanda. En el caso de España resultaba extraño imaginarse cómo un país de 15 millones de habitantes podria fabricar ferrocarriles para el transporte interno, sin ayuda por parte de Inglaterra ${ }^{70}$.

Las reclamaciones de los súbditos ingleses se apoyaban en su solicitud al Gobierno español para que considerase el problema desde el prisma de

70 Powles al Ministro de Finanzas (calle de Pontejos). Londres, 11 de octubre de 1858, AHN, legajo 5.602 . 
la justicia y la política, haciendo hincapié en el hecho de que las Compañias industriales de Madrid y Barcelona estaban convencidas de la conveniencia, para el comercio y crédito de España, de llegar a un arreglo definitivo. Los Tenedores de Certificados achacaban la falta de solución del problema a haber sido examinado desde el prisma de los partidos, y no como un tema fuera de la política y consiguientemente de los partidos. No creian conveniente que los súbditos ingleses se entremezclaran en los asuntos internos de España, ya que habian prestado su dinero a la Nación, a través de su Gobierno.

Argüian, como solución, que lo único que podia hacerse era nombrar una Comisión de las Cortes, compuesta por todos los partidos representados allí para que examinara el informe, evitando toda responsabilidad individual. Europa se decantaba por encontrar una solución rápida -pensamiento compartido por la opinión pública- y aducía que, tanto los paises que mantenian relaciones comerciales con España, como aquellos que no lo hacían, se habían visto desagradablemente sorprendidos por el Real Decreto de 1851, y lo habian considerado como un golpe contra el crédito de las naciones europeas. Estas mismas naciones consideraban que en el año 1859, la nación española se encontraba en posición desahogada y que sus rentas habian aumentado progresivamente a lo largo de los últimos años ${ }^{71}$.

En este sentido se propuso la recomendación de presentar un Memorial a la consideración del Gobierno español, suscrito por la Comisión y apoyado por las diferentes Compañías industriales comprometidas en promocionar la construcción de los ferrocarriles españoles, ya que estaban interesadas en el éxito del tema, porque redundaría beneficiosamente en las empresas industriales del país ${ }^{72}$. Dado que había sido desatendida la reclamación del año 1858, el Principal Secretary of State for Foreign Affairs of the Queen fue quien dio las instrucciones para que se presentara un nuevo Memorial al Ministro de Finanzas español José Salaverría ${ }^{73}$.

No obstante el tiempo transcurrido, y las sucesivas reclamaciones de los Tenedores de Certificados desde 1851, se llegó al año 1863, siendo Presidente del Consejo de Ministros, el Marqués de Miraflores, sin haber

7: Powles al Primer Secretario de Estado, Londres, 17 de marzo de 1859, AHN, legajo 5.602.

72 ANDREW BUCKANAN, Comite de Tenedores de Certificados a Saturnino Calderón Collantes Londres, 18 de marzo de 1859, AHN, legajo 5.602

73 Andrew Buckanan a Saturnino Calderón Collantes, Londres, 25 de abril de 1860, AHN, legajo 5.602 . 
dado una solución satisfactoria al tema, pese a las reiteradas y justas reclamaciones de los Tenedores de Certificados. Se achacaba la demora a que las circunstancias en que se fijó la Deuda no fueron perfectamente comprendidas, creyendo la Comisión que había llegado el momento de poner en manos de 7 distinguidos letrados españoles, un estado completo de los hechos ocurridos, a fin de recabar su opinión sobre el tema. Entre estos letrados se encontraban: Cirilo Alvarez, L. J. G. Acevedo, Manuel Cortina, José de Olázaga, J. F. Pacheco, L. Díaz Pérez y A. del Riveiro Cidraque.

Según el Presidente del Comité, estos abogados coincidieron unánimemente en declarar que: "ningún Estado puede actuar destruyendo los derechos de los acreedores sin su consentimiento. Los acreedores en este caso, no sólo no consintieron en la destrucción de sus derechos, sino que además entregaron su solemne protesta - la cual era sobradamente conocida por el Gobierno español- La aceptación del pago de la mitad del interés (pagado a través de unos Bonos comercializados al 20\%) no absolvía al Estado de su obligación de pagar la otra mitad y, consecuentemente, la responsabilidad del pago de la mitad del interés no pagado por el Estado permanecia completa y entera". A tenor de estas declaraciones, el Comité consideraba que lo único que se solicitaba era el pago de la Deuda.

Con los acontecimientos posteriores a 1851, la oposición del moderado O'Donnell a las medidas adoptadas por Luis Sartorious, conde de San Luis, entre las que se contaban: la disolución de las Cortes, amordazamiento de la prensa y destierro de generales contrarios, produjo la "Vicalvarada" y posteriores alzamientos de los progresistas en Barcelona, Valladolid, Zaragoza y Madrid, que inclinaron la balanza en favor de los pronunciados.

Desde Inglaterra los Tenedores de Certificados viendo el devenir de los acontecimientos y las dificultades económicas por las que pasaba la Nación española, dejaron la discusión del asunto en suspenso, permaneciendo a la espera de otras épocas más prósperas y favorables para todos. Los súbditos ingleses pensaron que ya habia llegado el momento oportuno de satisfacer la Deuda durante el Gobierno largo de O'Donnell, puesto que la coyuntura económica era claramente expansiva, gracias a la movilización de capitales a gran escala, principalmente dirigido hacia las inversiones ferroviarias, lo que había creado un clima general de prosperidad. Los Tenedores de Certificados calcularon que desde 1857 a 1863, la Tesorería española había aumentado notablemente y que pocos países europeos se habian recuperado económicamente en cifras de millones de libras como la Nación española. 
Con la llegada del Marqués de Miraflores a la Presidencia del Gobierno, se dio un nuevo impulso para la finalización de la Deuda, pues consideraba de una gran importancia su resolución a corto plazo. En este punto y con las consideraciones anteriores, el Comité pensó que no existía ningún motivo para prolongar el pago de la deuda por más tiempo, siendo un acto de estricta justicia, y permaneciendo España en una posición respetable. Para el Marqués de Miraflores, según y cómo lo expresó a la Cámara, «el crédito público era el alma y la vida de las naciones». Para el Comité, el año 1863 fue un momento muy adecuado para que se liquidara la Deuda con una antiguedad de 13 años de acuerdo con las conveniencias financieras de España y el interés de los acreedores ${ }^{74}$.

El Comité de Tenedores de Certificados temía que, continuando con los hechos notoriamente injustos sustentados por España, se la excluyera continuadamente de su segura participación en las Compañias industriales (creadas desde Agosto de 1851) en las principales Bolsas europeas. Se hacía referencia al hecho sucedido en 1852, momento en que el Gobierno español debería haber pagado una suma de dinero a los extranjeros y tal y como apareció en prensa, hizo el pago de Bonos del $3 \%$ con un promedio del $49,76 \%$. Se tenía la presunción de que, considerando las prósperas condiciones económicas de España, estos Bonos tendrian un valor de mercado del $60 \%$. Con esta simple transacción, España incurriría en una deuda permanente 5 veces mayor que la necesaria.

Los problemas del Gobierno español en materia económica venian determinados por las grandes cantidades de dinero que se habian pagado y continuaban pagándose en concepto de subvenciones a los contratistas de Ferrocarriles. Las obligaciones del Gobierno para con los contratistas se habían estimado según el precio de mercado. Este precio estaba regulado por los de otros valores públicos producidos en el mercado y era fácilmente comprensible lo que sucedería si las obligaciones fueran admitidas a la libre circulación en las Bolsas europeas. Todo ésto se traducía en un aumento de la Deuda permanente, sin ninguna necesidad y sin obtención de ventaja alguna.

El Comité recordaba al Gobierno español que España necesitaba el triple de las comunicaciones por ferrocarril de las que poseía en 1863 , si se comparaba con la proporción existente entre población y terrocarriles

14 POWLES, Presidente del Comité de Tenedores de Certificados españoles al Marqués de Miraflores, Presidente del Consejo de Ministros, Londres, 16 de abril de 1863, AHN, legajo 5.602. 
de los demás estados europeos, incluso contando con la finalización de los trabajos en marcha.

Las Compañias comprometidas con las Obras Públicas en España, se quejaban de que al estar excluídos de las Bolsas europeas, se sentían incapaces de conseguir las facilidades económicas que otros disfrutaban. El problema, no sólamente se centraba en la construcción de kilómetros de ferrocarriles, sino también en la existencia de cientos de acres de tierra que necesitaban ayuda en forma de irrigación para quintuplicar su valor. Lógicamente, para acometer todas estas obras era imprescindible la obtención de capital, el cual existía fuera de las fronteras españolas, en Europa, y que además podría dirigirse rápidamente hacia España, pero ella misma se autoexcluia.

Para el Comité de Tenedores de Certificados españoles, estos Certificados no constituian por sí sólos una reclamación a la Nación española, ya que la responsabilidad del Gobierno español residia en la Deuda misma. Los Certificados representaban la proporción que cada acreedor poseía en esta Deuda, independientemente de que el Gobierno español llegara a liquidarla, ya que se había convertido en un asunto de estricta necesidad.

El Comité argüía que los Certificados habían sido vendidos últimamente a precios desproporcionados en comparación con su valor real, debido principalmente a dos causas, $1^{a}$ ) la presión sufrida por los Acreedores (Tenedores) que se habian visto obligados a vender a cualquier precio y $2^{\circ}$ ) el depreciado crédito de España. Esto mismo ha ocurrido en épocas recientes en otros valores españoles.

Los Bonos del pasivo de la Deuda que estaban en 1863 al $30 \%$ interior de la Deuda, se habían vendido al $4 \%$ y los Bonos del $3 \%$ interior de la Deuda que en 1863 estaban al 50\%, se vendieron anteriormente al $19 \%$.

Existían muchos tenedores que nunca se habían decidido a vender ni uno sólo de los Certificados, porque siempre hab an esperado que algún día llegara la hora de la justicia. Según el Comité, España continuaba sin satisfacer su deuda, ya que nunca la había pagado directa o indirectamente. Cuando España necesitó dinero, lo pidió prestado - la mitad del interés lo pagó (aunque de una manera modificada) -, mientras que el resto todavía estaba pendiente. Para el Comité no era difícil efectuar un plan que pudiera satisfacer conjuntamente a los acreedores y a la nación española.

La cantidad total de intereses debida hasta el 30 de junio de 1851 era, según el Comité, de 8.112.537 de libras y estaba repartida entre Acreedores ingleses, holandeses y españoles. Aunque según la ley 
vigente debería devolverse en dinero esta cantidad a los Acreedores, el Comité pensaba que estos Acreedores aceptarían, en caso de devolución, que se efectuara el pago en Bonos del mismo carácter que los expedidos por la primera mitad, aunque se tenía la esperanza de que se aumentaría como una compensación razonable, teniendo en cuenta la pérdida de interés sufrida desde 1851 hasta el 1863. Suponiendo que el interés de la Deuda en el año 1863 fuera del $214 \%$, la cantidad total de interés sería de 182.558 libras y para el año 1870 se habrian convertido en 243.406 libras, lo que habría de sumarse al interés debido como compensación por la pérdida de interés durante los años transcurridos.

Según el Comité, la Deuda se habria incrementado de 13 a 22 millones de libras, cantidad que la nación española podría sufragar aumentando su hacienda mediante la admisión de capital extranjero, que serviría para fomentar sus Compañías industriales, pudiendo obtener estos medios a través de la creación de Deuda anual que habría de crear para la liquidación de su reclamación. Para el Comité sería muy satisfactorio que se restablecieran los intercambios monetarios entre las dos Naciones y que España recuperara su primitiva posición entre las demás naciones europeas ${ }^{75}$.

75 Powles al Marqués de Miraflores, Londres, 4 de junio de 1863, AHN, legajo 5.602. 